\title{
SURGICAL MANAGEMENT OF THE NEUROGENIC BLADDER AND BOWEL
}

\author{
GERALD C. MINGIN, LAURENCE S. BASKIN \\ Pediatric Urology, Children's Hospital, University of California, San Francisco, California, USA
}

\begin{abstract}
Spina bifida and myelodysplasia are associated with neurogenic abnormalities of the bladder and bowel function. All children with myelodysplasia require an evaluation of their urinary tract with ultrasound and urodynamics to confirm normal bladder and kidney function. Patients with anatomical and functional abnormalities require treatment, the mainstay being intermittent catheterization and anticholinergic medication. The treatment goals for patients with a neurogenic bladder are the preservation of the upper urinary tract, bladder and bowel continence, independence, autonomy, and facilitation of self-esteem. A minority of children will not respond to conservative therapy and will ultimately require surgical intervention. This review will discuss the surgical options for bladder augmentation, bladder neck reconstruction and closure, as well as the methods for the creation of continent catheterizable stomas. The timing, indications, and description for each procedure will be addressed. Finally, the antegrade continence enema procedure will be described for the management of refractory fecal incontinence.
\end{abstract}

Key words: bladder; bowel; neural tube defects; bladder, neurogenic; therapeutic; surgery

Int Braz J Urol. 2003; 29: 53-61

\section{INTRODUCTION}

The most common etiology of patients with a neurogenic bladder is myelodysplasia, which occurs in approximately 1 in 1,000 births in the United States (1). Myelodysplasia is a spectrum of diseases ranging from severe motor and neurogenic abnormalities affecting ambulation, bowel and bladder function, to more minor defects such as an asymptomatic tethered chord.

All patients with myelomeningocele should have an evaluation of their urinary tract in order to confirm normal bladder and kidney function. This is especially true in ambulatory patients, where $95 \%$ will have evidence of neurogenic bladder (2). Urologic treatment of myelomeningocele includes defining the status of the bladder and upper tracts by renal bladder ultrasound and urodynamics. In patients with a hostile bladder, early intermittent catheterization is instituted $(3,4)$. For patients with a low leak point pressure watchful waiting is acceptable. In both cases, the goal is to preserve the upper tracts. Subsequent efforts are focused on both bladder and bowel continence. Prior to starting kindergarten and elementary school, the common goal of parents and the health care team is to render these children continent of both bladder and bowel. This preserves the child's autonomy and improves self-esteem. Fortunately, this can be achieved in the majority of patients with adequate bladder emptying through intermittent catheterization and the use of anticholinergic medications. Bowel continence can typically be achieved with diet, oral medication, or routine enema use. A minority of patients will not respond to medical therapy, and will require surgical intervention to achieve renal preservation, as well as bladder and bowel continence. The 
aim of this paper is to review the surgical treatment of patients with neurogenic bladder and bowel.

\section{TIMING OF SURGERY}

The most important aspect in the treatment of patients with myelodysplasia is preserving renal function. Urodynamic evaluation reveals that approximately $27 \%$ of patients have poor outlet resistance alone, and can be managed with observation. Sixtytwo percent have failure to coordinate their bladder and sphincter, with hypertonicity/spasticity and poor emptying. These children will require intermittent catheterization and anticholinergic medications. The remaining $10 \%$ have flaccid bladders and sphincter dysinergia, which may develop spasticity or hypertonicity and require intermittent catheterization and anticholinergic medications (5). Regardless of medical management, a few patients in the neonatal and early years may have recurrent infection or increasing hydronephrosis. In these cases, vesicostomy is a useful surgical adjunct. We advocate the classic Blocksom technique (Figure-1). Vesicostomy allows the neurogenic bladder to cycle while keeping the pressures low. During a bladder contraction with inappropriate sphinc- ter contraction (in the absence of a vesicostomy) the increased pressure will pop off into a refluxing kidney, or alternatively cause increasing hydronephrosis. Reconstruction with closure of the vesicostomy and augmentation is typically performed when the child begins school, when the patient and the family are ready to accept the responsibilities of intermittent catheterization.

Patients that continue to have stable renal function without recurrent infection are monitored until they start school. At that time careful assessment of bowel and bladder continence is performed. There are some variations in the exact age when continence is sought after depending on developmental issues, family support, and patient and family compliance. Usually we recommend attaining continence between 5 and 7 years of age.

\section{PREOPERATIVE PLANNING}

We have been strong advocates in the initiation of neonatal intermittent catheterization for patients with myelomeningocele (6). We feel that the concept of intermittent catheterization is well ac-
A

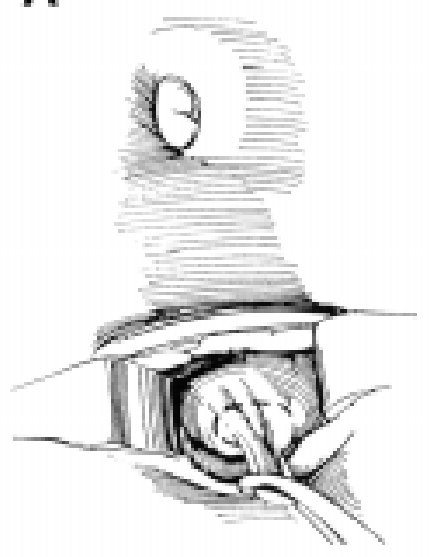

B

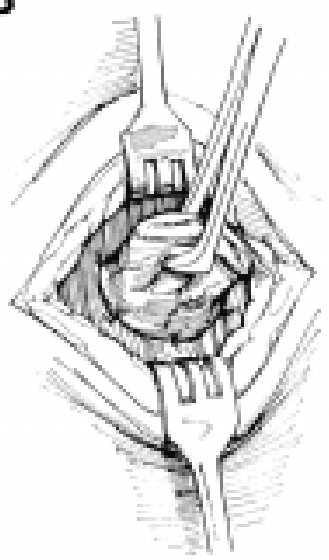

C

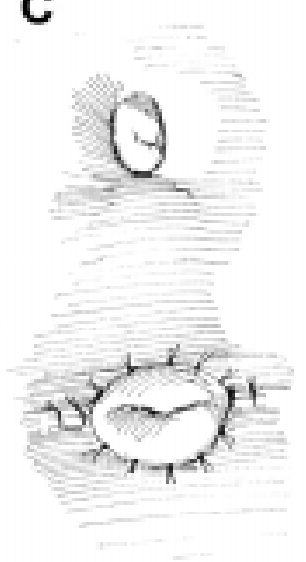

Figure 1 - Blocksom vesicostomy. A) The skin, rectus fascia, and muscle are divided. The urachus is identified and pulled into the wound. $B$ ) and $C$ ) The urachus is excised, the posterior and anterior serosa of the bladder are approximated to the rectus fascia, and the bladder mucosa is approximated to the skin. (From Hinman F Jr: Atlas of Pediatric Urology. Philadelphia, W.B. Saunders Co., 1994, with permission). 
cepted by parents with a newborn baby presenting spina bifida. The psychological consequences of the early initiation of catheterization facilitates its latter acceptance. Since eventual continence is almost always dependent on catheterization, we do not hesitate to introduce the concept at birth. Parents and children who are catheterizing early are better prepared to accept and handle reconstruction. Early institution of catheterization also improves bladder compliance and decreases the need for augmentation $(3,6)$.

When the patient and his/her family are prepared to accept the requirements associated with continence, an assessment of the bladder and urinary sphincter is required. Two key questions must be answered. First: is the bladder volume acceptable and the urinary sphincter competent, or does the child require augmentation and/or an outlet resistance procedure to achieve continence (7)? For example, a patient with marginal capacity may have an outlet that is insufficient to achieve continence. With augmentation, however, the compliance will improve and the outlet then becomes sufficient to keep the patient dry. The status of the patient's ambulation is also important. Ambulatory patients with myelodysplasia have increased intra-abdominal pressures, and therefore require greater outlet resistance to achieve continence.

Prior to surgical correction of incontinence, urodynamic evaluation with fluoroscopic imaging is recommended. Bladder capacity prior to leakage is compared to expected capacity (7). Sphincter function is assessed by radiologic evaluation of the bladder neck. An open bladder neck throughout filling is unlikely to provide continence, and will require surgical correction (Figure-2). Since emptying in patients with a neurogenic bladder will require intermittent catheterization, preoperative assessment determines whether catheterization will be performed through the urethra or an abdominal stoma will be necessary. It has been our bias that patients who require extensive bladder neck reconstruction be provided with an abdominal stoma to assure catheterization. In achieving continence (defined as the ability to wear normal undergarments without protection), we have found that even properly performed bladder neck reconstruction can make routine catheterization less than $100 \%$ reliable. Since catheterization is critical for the

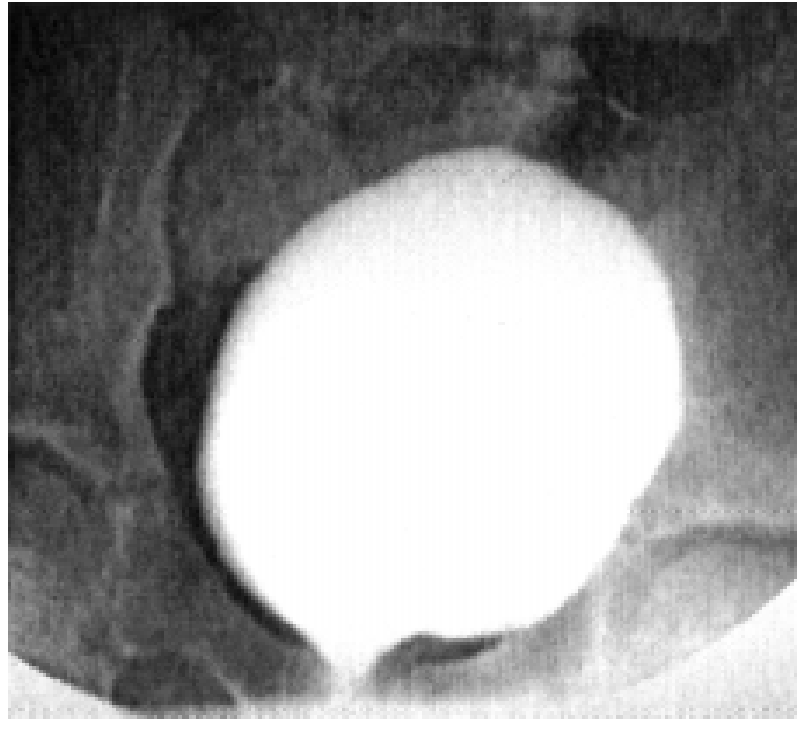

Figure 2 - Radiograph during the filling phase showing open bladder neck.

patient's safety, an abdominal stoma reduces the risk of the patient being unable to empty his/her reservoir.

Preoperative assessment also includes documenting the presence of vesicoureteral reflux, which can be detected during urodynamics. Although augmentation may itself lead to reflux resolution, it has been our preference to reimplant refluxing ureters at the time of augmentation (8). This can be done safely with little increase in the operative time, leading to complete resolution of reflux (9).

\section{BLADDER AUGMENTATION}

Historically, many different segments of bowel have been used for bladder augmentation. The ideal segment should be lined with urothelium, making ureterocystoplasty an excellent choice. However, it is unusual for a patient to have a nonfunctional segment amenable to this type of reconstruction. There have been multiple attempts to maintain urothelial lined structures, such as autoaugmentation or autoaugmentation with demucosalized sigmoid, ileal, or gastric patches (10-14). Evidence exists that would not support placing intestinal stroma in contact with urothelium (15). This may create abnormal cellular signaling between cell types that are normally not in contact with each other, leading to cellular pheno- 
typic changes. For example, intestinal stromal influences of the bowel are likely to change the urothelium to an intestinal phenotype overcoming the purpose of composite augmentations (15).

Intensive work is also currently in progress with tissue matrices, either homotypic acellular or heterotypic intestinal scaffolds $(16,17)$. Autologous cultured urothelium may improve the outcomes, but so far, tissue engineering has not proven to be clinically successful.

The most commonly used segment for augmentation is ileum. Classic clamshell augmentation cystoplasty has been utilized successfully both in adults and in children. It is important to isolate the segment at least $10 \mathrm{~cm}$ from the ileocecal valve, so as not to interfere with bowel control, especially in patients with myelodysplasia who already have bowel continence issues. Detubularization on the anti-mesenteric border provides a low-pressure reservoir and increases capacity when fashioned into either a U or W- shape (18). The bladder plate needs to be widely opened to prevent an hourglass deformity when anastomosing the patch to the bladder (Figure-3). Sigmoid augmentation has also been successful, although there are reports of increased rhythmic contractions when this segment is used (19). In select cases, gastric augmentation has been quite successful. Proper patient selection, which includes neurogenic patients who are insensate, is critical to avoid the clinical syndrome of hematuria/dysuria. Gastric augmentation has the advantage of less mucous production and less changes in metabolic parameters (20).

Patients with ileal augmentation are subject to metabolic acidosis, mucous production, and urolithiasis, as well as a risk of cancer at the anastomotic site $(21,22)$. We have recently shown that metabolic changes do not have an adverse affect on linear growth or bone density in children undergoing augmentation (23). Finally, patients with any type of intestinal augmentation are at risk for perforation, especially if compliance with catheterization is sub-optimal $(24,25)$. Any patient undergoing an augmentation should wear a medical alert band as a reminder of the risk of bladder perforation. This will serve to warn medical personal that abdominal pain should initiate a work-up to ensure an intact augmentation cystoplasty.

\section{BLADDER NECK CONTINENCE RECONSTRUCTION}

In children with poor urethral outlet resistance, bladder neck reconstruction may be necessary to obtain continence. The literature is filled with a myriad of papers describing different methods to increase urethral resistance, while at the same time allowing ease of catheterization. In our experience, none of these procedures is fully proven.

In females, our choice has been a fascial sling placed just distal to the bladder neck, with the concomitant creation of an abdominal stoma (Figure-4). The sling can be placed abdominally, which is our choice, if a concomitant augmentation is performed. To safely identify the space between the urethra and the vagina (urethra and rectum in males), the posterior midline approach behind the bladder is used (26). In patients with adequate bladder compliance, the sling can be placed by a vaginal approach. Recently, human cadaveric fascia and xenotropic sling material has become available, avoiding the need for an abdominal incision and autologous sling harvest (27). We have been successful in catheterizing the urethral sling in the majority of our female patients. Occasionally, we have utilized the Mitrofanoff principle providing an abdominal stoma for catheterization.

In males, we have not found one operation that can be applied to every patient. Our choices include either the Young-Dees Leadbetter (Figure-5), or a modified Kropp bladder neck tube (Figure-6) (28). The Young-Dees Leadbetter procedure is performed by reimplantation of the ureter to a higher position in the bladder, and tubularization of the mucosa over a $5 \mathrm{~F}$ feeding tube. In both the Young-Dees and Kropp procedures, augmentation cystoplasty is typically performed at the same setting with a catheterizable abdominal stoma thus avoiding any issues with catheterization.

\section{ARTIFICIAL URINARY SPHINCTER}

The artificial urinary sphincter is a useful adjunct in gaining urethral continence. We have had long-term success in both patients with and without augmentation (3). The disadvantages of the artificial 
A

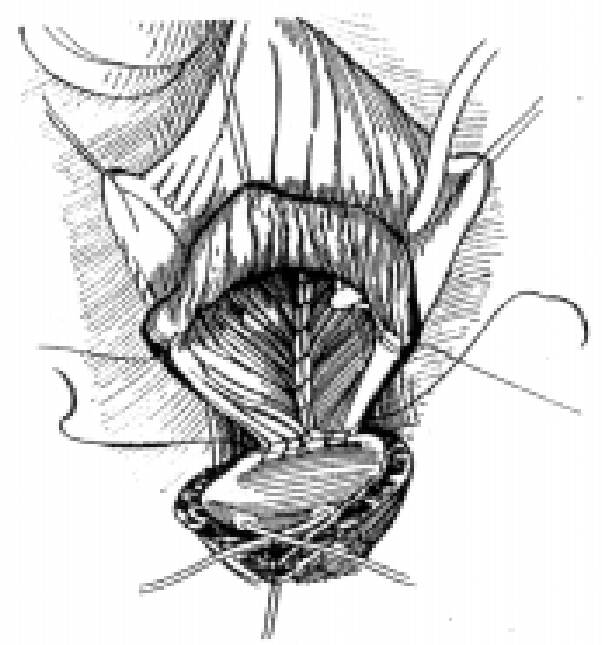

B

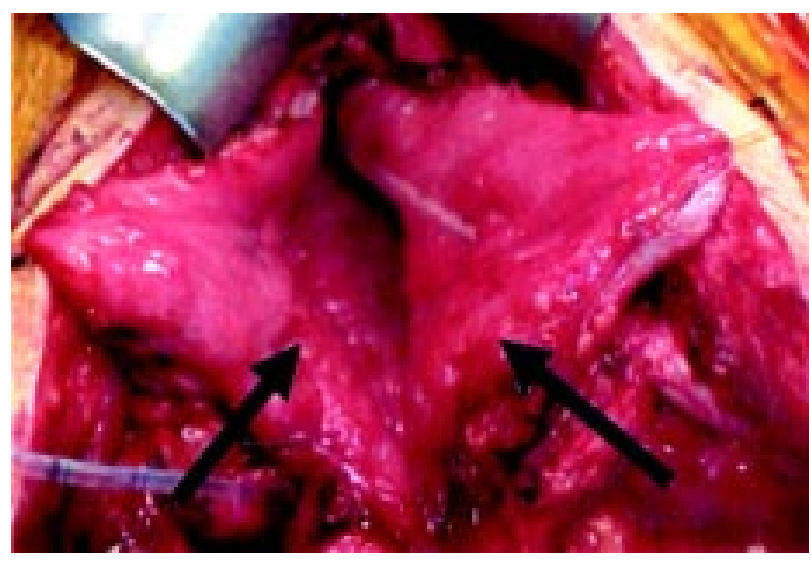

Figure 3 - Anastomosis of the bowel segment to an open bladder plate. A) Diagram of the open bladder. B) Intra-operative photo of the clamed shelled bladder, with arrows pointing to each bladder half. (From Hinman F Jr: Atlas of Pediatric Urology. Philadelphia, W.B. Saunders Co., 1994, with permission).

A

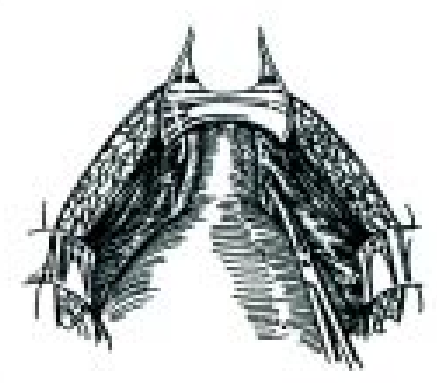

B

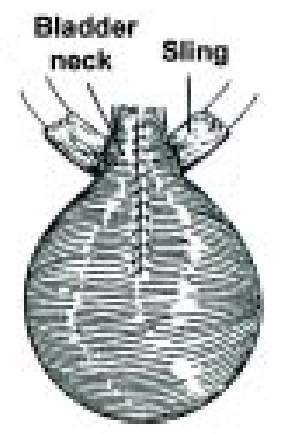

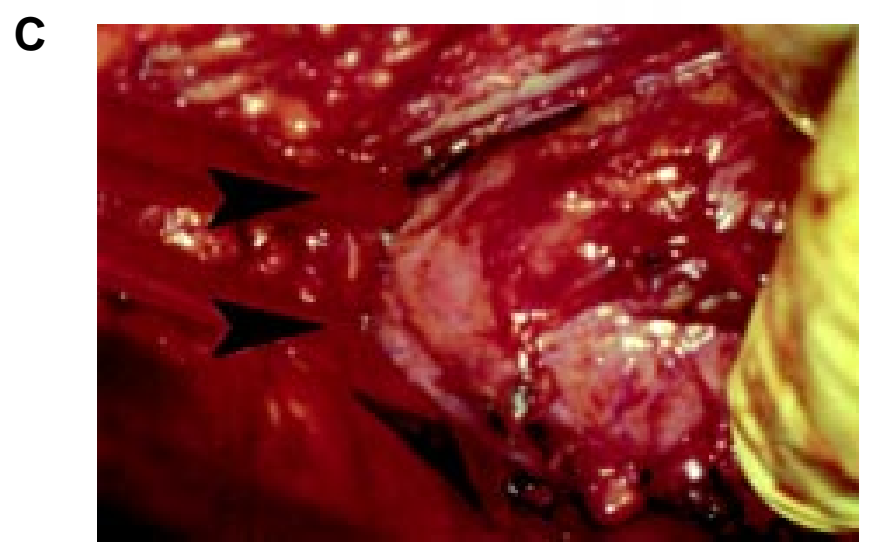

Figure 4 - Placement of the fascial sling around the bladder neck. A) Diagram showing incision of the endopelvic fascia. B) Diagram showing the fascial sling around the bladder neck. C) Intra-operative photo with arrows indicating the position of a vessel loop around the bladder neck. (From Elder JS: Sling Procedure. Atlas of the Urologic Clinics of North America, 2000, with permission). 


\section{NEUROGENIC BLADDER AND BOWEL}

A

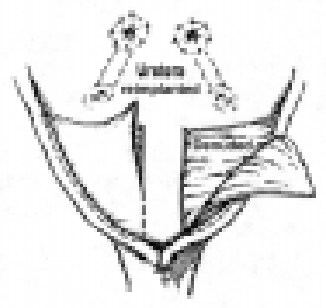

B

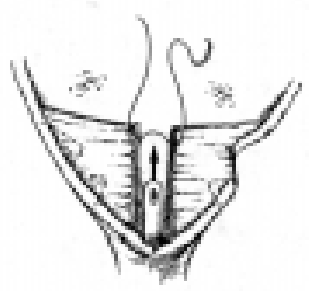

C

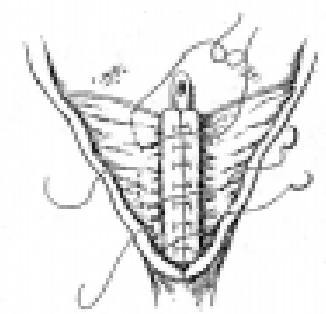

D

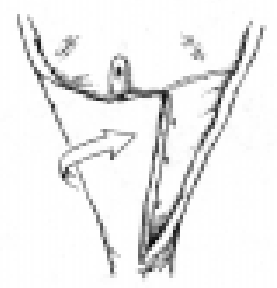

Figure 5 - Diagram of the Young-Dees Leadbetter bladder neck reconstruction. A) The bladder is opened and the bladder mucosa denuded, leaving a strip of mucosa. B)The mucosal strip is anastomosed over a catheter. $C$ ) and D) The bladder muscle is reaproximated in pants-over-vest fashion. (From Gearhart JP: Modified Young-Dees Leadbetter Procedure for Urinary Incontinence in the NonNeurogenic Bladder. Atlas of the Urologic Clinics of North America, 2000, with permission).

sphincter include infection, which requires removal, as well as the need for replacing pump reservoir and tubing should malfunction occur. The average lifespan of the artificial sphincter is 8 years, all but guaranteeing eventually replacement. In prepubertal children, the cuff must be placed at the bladder neck, while post-pubertally it can be placed around the bulbar urethra.

\section{BLADDER NECK CLOSURE}

Bladder neck closure is a last resort in those patients who have undergone alternative procedures with refractory incontinence. The procedure can be performed retropubically, transvesically, or transvaginally in girls. This procedure is done in combination with the creation of an abdominal stoma, and can be difficult in patients with previous bladder neck surgery. The amount of scarring often requires opening the bladder to gain access to the bladder neck. The key to a successful operation is wide mobilization of the bladder neck, and interposition of healthy tissue between the closed bladder neck and urethral stump. Omentum is the preferred tissue. Our long term results illustrate the difficulty of the procedure (29).
A

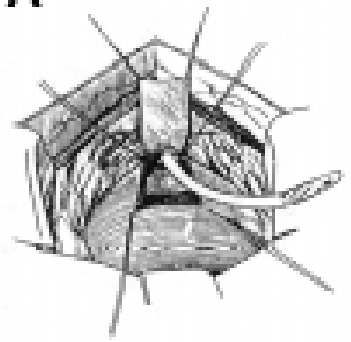

B

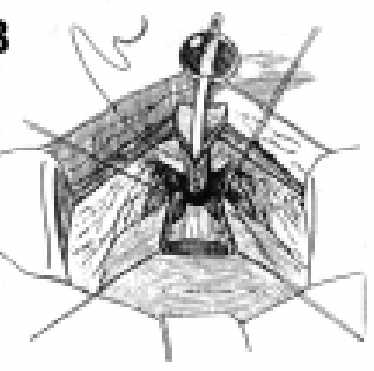

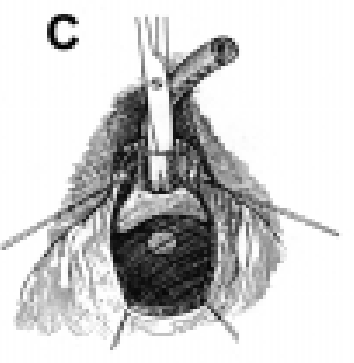

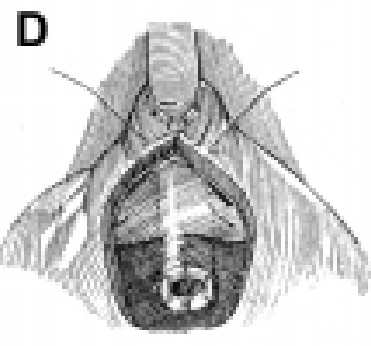

Figure 6 - Diagram of the Kropp bladder neck reconstruction. A) and B) The bladder is opened and a strip of anterior bladder wall in continuity with the bladder neck is excised and rolled into a tube over a catheter. C) and D) A submucosal tunnel is constructed along the bladder floor through the trigone, and the elongated urethra is reimplanted as shown. (From Pippi Salle JL. Urethral Lengthening for Urinary Incontinence. Pediatric Urology. Philadelphia, W.B. Saunders Co., 2001, with permission). 
A

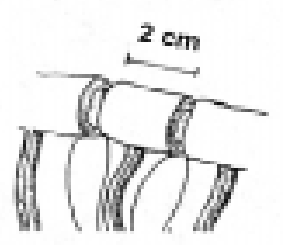

B

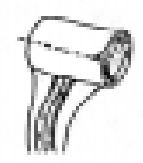

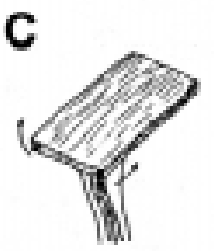

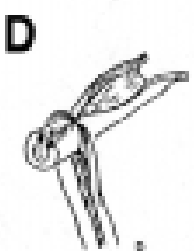

Figure 7 - Diagram of the classic Monti procedure. A) and B) A $2 \mathrm{~cm}$ ileal segment is isolated and then opened on its anti-mesenteric border. B) Detubularization on the antimesenteric side of the segment. C) and D) The flap is then transversely tubularized over a catheter. (From Monti PR: New techniques for construction of efferent conduits based on the Mitrofanoff principle. Urology 1997, 49:112-5, with permission).

\section{CATHETERIZABLE STOMAS}

All continent catheterizable stomas employ a flap valve (Mitrofanoff) principal to maintain continence. Continence is achieved as the bladder fills and the intravesical pressure is transmitted to the conduit (30). We prefer the appendix. The proximal end is brought out to the abdominal wall, either through the lower quadrant or through the umbilicus, and is spatulated and anastamosed to a U-shaped skin flap created to prevent stenosis. If appendix is not available, ileum and colon can also be fashioned into a conduit utilizing the Monti procedure (31). In the classic Monti procedure (Figure-7), a $2 \mathrm{~cm}$ segment of ileum or colon is isolated and opened on the antimesenteric border and retubularized; if the length is inadequate, 2 segments can be fashioned and anastamosed to each other. Alternatively, a single segment can be split in the middle, opened from opposite ends, and rolled over a feeding tube to create a spiral Monti (Figure-8). This provides adequate length in most cases, avoiding the need to harvest 2 separate intestinal segments.

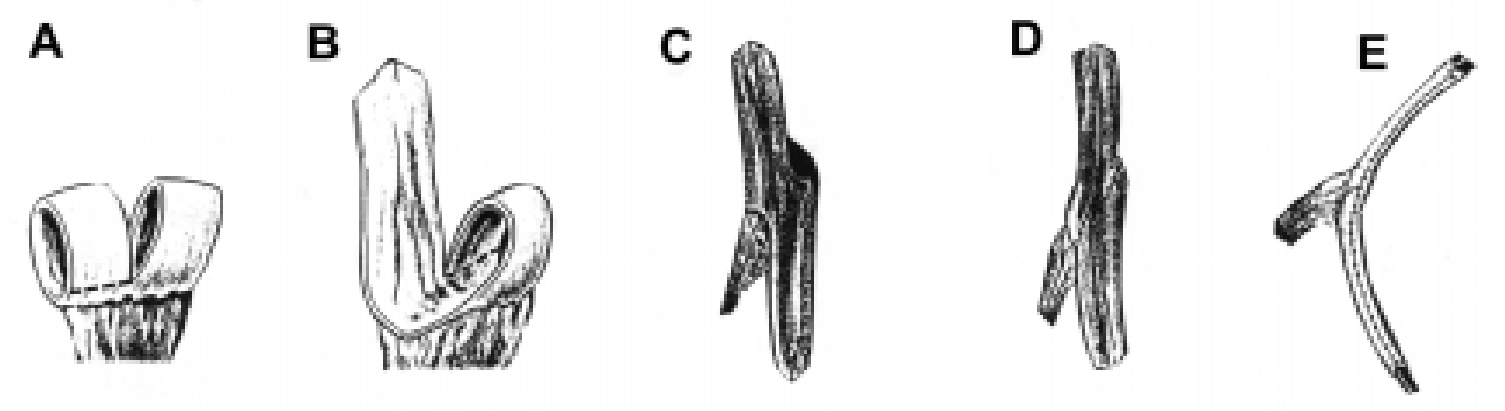

Figure 8 - Spiral Monti. A) and B) A segment of the ileum is isolated just as in the classic Monti. However, an opening is made both in the middle of the segment and on the anti-mesenteric border as shown. The flap is tubularized transversely. (Indiana School of Medicine, 2000, with permission). 
A newer technique, which is gaining widespread acceptance is augmentation with combined abdominal stoma that is devised from an eccentric Ushaped ileal patch (Macedo procedure, Figure-9) (32). The advantage of the Macedo procedure is that a separate segment of bowel is not required for the Monti procedure.

\section{NEUROGENIC BOWEL - ACE MALONE}

In children who have failed conservative management of their fecal incontinence, the same Mitrofanoff and Monti principals can be applied to the creation of an antegrade continence enema (ACE) (33). The appendix can be brought out through the umbilicus or the lower quadrant; if unavailable, a 2 $\mathrm{cm}$ segment of ileum or colon can be substituted for the appendix. The appendix or tubularized bowel is imbricated or reimplanted into the cecum or large bowel in an antirefluxing fashion to prevent leakage of stool or flatus.

\section{CONCLUSION}

In patients with myelodysplasia, the primary goal is preserving upper tract function with concomitant attainment of urinary and fecal continence. In order to accomplish these goals, each child requires evaluation, with the institution of intermittent catheterization and/or medical therapy from early childhood. If the child develops recurrent infection or increasing hydronephrosis early on, a vesicostomy is needed until the child is old enough for reconstruction. Otherwise, patients should be followed until school age when continence issues can be addressed. Only when the patient and his/her family are ready and understand the consequences of surgery, should augmentation, bladder neck reconstruction, or the creation of a continent catheterizable stoma be performed.

\section{REFERENCES}

1. Bauer SB: Neurogenic bladder dysfunction. Pediatric Clin North Am. 1987; 34:1121-32.

2. Mevorach RA, Bogaert GA, Baskin LS, Lazzaretti CC, Edwards MS, Kogan BA: Lower urinary tract function in ambulatory children with spina bifida. Br J Urol. 1996; 77:593-6.

3. Sutherland RS, Mevorach RA, Baskin LS, Kogan BA: Spinal dysraphism in children: an overview and an approach to prevent complications. Urology 1995; 46:294-304.

4. Teichman JM, Scherz HC, Kim KD, Cho DHP, MG, Kaplan GW: An alternative approach to myelodysplasia management: aggressive observation and prompt intervention. J Urol. 1994; 152:807-11.

5. Baskin LS, Kogan BA, Benard F: Treatment of infants with neurogenic bladder dysfunction using anticholinergic drugs and intermittent catheterization. Br J Urol. 1990; 66:532-4.

6. Wu H, Baskin LS, Kogan BA: Neurogenic bladder dysfunction due to myelomeningocele: neonatal versus childhood treatment. J Urol. 1997; 157:2295-7.
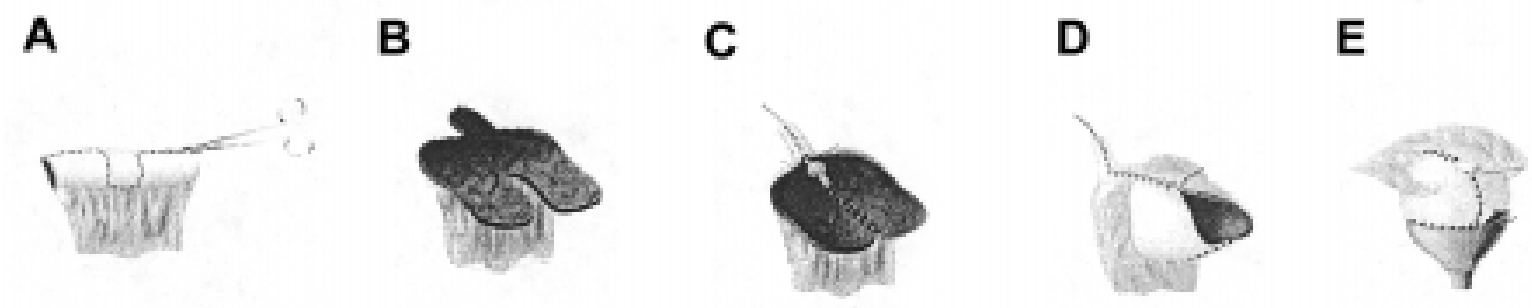

Figure 9 - Diagram of the Macedo procedure. A) A $3 \mathrm{~cm}$ segment of ileum is first isolated. It is then opened on the anti-mesenteric border, taking care to isolate a $3 \mathrm{~cm}$ segment from the anterior part of the ileum. B), C) and D) The $3 \mathrm{~cm}$ segment and ileal plate are then tubularized. E) The continence valve mechanism is created by embedding the tube over a serous-lined extramural tunnel. (From Macedo A, Srougi M: A continent ileum-based reservoir. BJU Int. 2000; 85:160-2). 
7. Houle AM, Gilmour RF, Churchill BM, Gaumond M, Bissonnette B: What volume can a child normally store in the bladder at a safe pressure? J Urol. 1993; 149:561-4.

8. Nasrallah PH, Alilabad HA: Bladder augmentation in patients with neurogenic bladder and vesicoureteral reflux. J Urol. 1991; 146:563.

9. Nomura S, Ishido T, Tanaka K, Komiya A: Augmentation ileocystoplasty in patients with neurogenic bladder due to spinal cord injury or spina bifida. Spinal Cord. 2002; 40:30-3.

10. Cartwright PC, Snow BW: Bladder autoaugmentation: early clinical experience. J Urol. 1989; 142:505-8.

11. Cartwright PC: Bladder autoaugmentation: partial detrusor excision to augment the bladder without use of bowel. J Urol. 142:1050-3.

12. Dewan PA: Autoaugmentation demucosalized enterocystoplasty. World J Urol. 1998. 16:255-61.

13. Duel BP, Gonzalez R, Barthold JS: Alternative technique for augmentation cystoplasty. J Urol. 1998; 159:998-1005.

14. Nguyen DH, Mitchell ME, Horowitz MB, DJ Carr MC: Demucosalized augmentation gastrocystoplasty with bladder autoaugmentation in pediatric patients. J Urol. 1996; 156:206-9.

15. Li YW, Liu WH, et al.: Plasticity of the urothelial phenotype: effects of gastro- intestinal mesenchyme/stroma and implications for urinary tract reconstruction. Differentiation 2000; 66:126.

16. Sutherland RS, Baskin LS, Hayward SW: Regeneration of bladder urothelium, smooth muscle, blood vessels and nerves into an accellular tissue matrix. J Urol. 1996; 156:571-7.

17. Kropp BP, Rippy MK, Badylahak ST: Characterization of small intestine submucosa regenerated canine detrusor: an assessment of reinnervation, in vitro compliance and contractility. J Urol. 1996; 156:599-607.

18. Hinman F: Selection of intestinal segments for bladder substitution: physical and physiological characteristics. J Urol. 1988; 139:519-23.

19. Goldwasser B, Webster GD: Augmentation and substitution enterocystoplasty. J Urol. 1986; 135:215-24.

20. Bogaert GA, Mevorach RA, Kim A, Kogan BA: The physiology of gastrocystoplasty: once a stomach, always a stomach. J Urol. 1995; 153:1977-80.

21. Mitchell ME, Piser JA: Intestinocystoplasty and total bladder replacement in children and young adults: follow-up in 129 cases. J Urol. 1987; 138:579-84.

22. Eraklus AJ, Folkman MJ: Adenocarcinoma at the site of ureterosigmoidostomies for exstrophy of the bladder. J Pediatric Surg. 1978; 13:730-4.
23. Mingin GC, Nguyen HT, Mathias RS, Shephered JA: Growth and metabolic consequences of bladder augmentation in children with myelomeningocele and bladder exstrophy. Pediatrics 2002; 110:1193-8.

24. Sheiner JR, Kaplan GW: Spontaneous bladder rupture following enterocystoplasty. J Urol. 1988; 140:1157-8.

25. Rink RC, Woodbury PW, Mitchell ME: Bladder perforation following enterocystoplasty. J Urol. 1988; 139:234.

26. de Badiola F, Gosalbez R, Ruiz E, Sosa A, Labbie A: The posterior approach for bladder neck dissection. Br J Urol. 2000; 85:59.

27. Grossklaus DF, Shappell SB, Adams MC, Brock JW, Pope JC: Small intestinal submucosa as a urethral coverage layer. J Urol. 2001; 166:636-9.

28. Kropp KA: Kropp Urethral Lengthening. Atlas, Urol Clin North Am. 2001; 9:81.

29. Nguyen HT, Baskin LS: Is bladder neck closure the final surgery in children with severe urinary incontinence. Presented at the Society for Pediatric Urology, Orlando, Florida, 2002.

30. Mitrofanoff P: Trans-appendicular continent cystostomy in the management of the neurogenic bladder [in French]. Chir Pediatr. 1980; 21:297.

31. Monti PR, Lara RE, Dutra MA, Carvalho JR: New techniques for construction of efferent conduits based on the Mitrofanoff principle. Urology 1997; 49:112-5.

32. Macedo A Jr, Srougi M: A continent catheterizable ileal based reservoir. BJU Int. 2000; 85:160-2.

33. Malone PS, Ransely PG, Kiely EM: Preliminary report: the antegrade continence enema. Lancet 1990; 336:1217-8.

Received: August 7, 2002

Accepted: August 30, 2002 